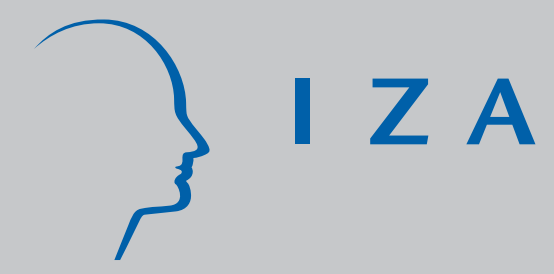

IZA DP No. 1543

The Interaction of Tax Exemptions and Individual Tax Reform Preferences

Salvatore Barbaro

J ens Südekum

March 2005 


\title{
The Interaction of Tax Exemptions and Individual Tax Reform Preferences
}

\author{
Salvatore Barbaro \\ University of Mainz \\ Jens Südekum \\ University of Konstanz \\ and IZA Bonn
}

\section{Discussion Paper No. 1543 \\ March 2005}

\author{
IZA \\ P.O. Box 7240 \\ 53072 Bonn \\ Germany \\ Phone: +49-228-3894-0 \\ Fax: +49-228-3894-180 \\ Email: iza@iza.org
}

\begin{abstract}
Any opinions expressed here are those of the author(s) and not those of the institute. Research disseminated by IZA may include views on policy, but the institute itself takes no institutional policy positions.

The Institute for the Study of Labor (IZA) in Bonn is a local and virtual international research center and a place of communication between science, politics and business. IZA is an independent nonprofit company supported by Deutsche Post World Net. The center is associated with the University of Bonn and offers a stimulating research environment through its research networks, research support, and visitors and doctoral programs. IZA engages in (i) original and internationally competitive research in all fields of labor economics, (ii) development of policy concepts, and (iii) dissemination of research results and concepts to the interested public.
\end{abstract}

IZA Discussion Papers often represent preliminary work and are circulated to encourage discussion. Citation of such a paper should account for its provisional character. A revised version may be available directly from the author. 


\section{ABSTRACT}

\section{The Interaction of Tax Exemptions and Individual Tax Reform Preferences*}

The individual voting behavior on the abolishment of single income-tax exemptions crucially depends on how strongly agents are affected by other deduction possibilities that are not at stake in the reform plans of the government. The interactions depend (i) on the shape of the tax schedule, and (ii) on how the government wants to use the revenue that is generated by the cut of tax privileges. If government plans to increase redistribution in form of lump-sum transfers, then the political chances of a tax reform increase with the existence of other deduction possibilities under progressive taxation. With proportional taxation and a budgetenlargement policy, the voting decision depends only on the particular tax privileges at stake. Matters are different if the government wants to adopt a revenue-neutral tax-cut-cum-basebroadening policy. Except for strong progression, it is less likely that an agent supports the elimination of tax privileges the stronger she is affected by other exemptions in the back.

JEL Classification: D72, D74

Keywords: income tax reform, public choice

Corresponding author:

Salvatore Barbaro

J.-Welder Weg 4

55099 Mainz

Germany

Email: barbaro@uni-mainz.de

\footnotetext{
*The authors are grateful to Florian Baumann, Arghya Ghosh, Lazlo Goerke, Martin Kolmar, Dorothee Schmidt, Nikolai Stähler, Georg Tillmann and Stefan Traub for several very useful discussions and comments. The usual disclaimer applies.
} 


\section{Introduction}

The claim for a simplification of income tax systems is ubiquitous in many countries, both in Europe and the United States (see e.g. Graetz (1999)). Tax laws consist of a huge number of complicated tax exemptions, e.g. for commuting, working at night, home offices etc, that are hard to comprehend even for specialists. In this paper we will look at tax reforms from the point of view of political economics. The focus that distinguishes our paper from existing work in this area is that we explicitly look at a "complicated" income tax system with several parallel deduction possibilities and analyse how the interaction of the single tax exemptions influences the individual voting decision on different reform proposals. Economists customarily propose a revenue neutral tax-cut-cum-base-broadening (tccbb), i.e. the cut of tax exemptions in exchange for lower tax rates (see, for instance, Hall and Rabushka (1985)). Politicians might also wish to abolish exemptions without cutting tax rates, in order to render more revenue that can be spent on redistribution. We label such a proposal a budget-enlargement (be) policy. We will compare both tax reform strategies from a political perspective.

In a complicated income tax system, the government will realistically not be able to abolish all exemptions at once, but will at most aim for the cut of some exemptions while leaving others unchanged. For example, the government might suggest to abolish the deductability of commuting expenses in exchange either for lower tax rates (tccbb) or in exchange for more redistribution (be). One would intuitively expect that the decision of a voter whether to support or reject this reform proposal is determined by how much she benefits from the particular deduction possibility at stake, i.e. by how much the voter commutes. However, in this paper we point to a mechanism in "complicated" income tax systems that has been overlooked so far. The central message is that the untouched deduction possibilities, which are not at stake in the government's proposal, play a key role for determining the decision of voters whether to support the tax reform or not. In other words, whether a voter supports or rejects the cut of the deductability of commuting expenses also depends on how much she works at night etc. The direction of the impact of these untouched exemptions firstly depends on the shape of the tax schedule (progressive, proportional, regressive). And secondly, it is different under a be- than under a tccbb-policy.

This paper is generally related to the literature that analyses (tax) reforms from a political economics perspective (Romer (1975); Roberts (1977); Meltzer and Richard (1981, 1983); Fernandez and Rodrik (1991); Konrad (2004)). Yet, none of these papers looks at the interaction of parallel deduction possibilities that shapes the individual voting decisions. One major insight from the literature on the political economics of reforms is that richer individuals are generally more reluctant to support reforms that aim at more redistribution in the society (see Harms and Zink (2003) for an overview). In our model, individuals do not only differ with respect to gross income, but also with respect to other tax relevant characteristics. Individual voting decisions are not primarily driven by differences in gross income, but by differences in taxable income. Furthermore, we derive results that stand in some contrast to that literature. We show that in some circumstances the agents' gross income is irrelevant for the individual decision whether to support or reject a be-reform that aims at more redistribution. 
Lastly, we are more general than most of the existing papers by (realistically) allowing also for non-proportional tax systems. Yet, we focus on the determination of individual voting decision in this paper and do not derive the voting results for the society as a whole. ${ }^{1}$

The remainder of this paper is structured as follows. We present the basic setup in Section 2, before analysing the individual voting decision on a budget-enlargement policy (Subsection 2.1) and the tax-cut-cum-base-broadening (Subsection 2.2). Section 3 concludes.

\section{The model}

Consider a population of $\mathcal{I}=[0,1] \subset \mathbb{R}$ heterogeneous individuals who differ with respect to gross endowed income, $y_{i} \in \mathbb{R}_{+} \forall i \in \mathcal{I}$, and with respect to $n>1$ taxrelevant characteristics (measured in monetary terms) that are denoted by $\theta_{j}$, where $j \in \mathcal{N}=\{1, \ldots, n\}$. Each agent $i$ can deduct $\theta_{i j} \geq 0 \forall j \in \mathcal{N}$ from her gross income in order to arrive at her individual tax base $x_{i} \equiv y_{i}-\sum_{j} \theta_{i j}$. We assume that $\theta_{i j}$ is exogenously given for any individual and does not depend on the properties of the tax system. $^{2}$ Furthermore, we assume that the single exemptions $\theta_{i j}$ as well as gross income $y_{i}$ are independently distributed across the voting population $\mathcal{I}$. The tax base $x_{i} \in \mathbb{R}$ follows some distribution function $F(x) .^{3}$

A tax schedule $T(x): \mathbb{R}^{n+1} \rightarrow \mathbb{R}_{+}$is defined, which is assumed to be continuous, monotonous and twicely differentiable in $x$. The marginal tax rates are strictly positive and do not exceed unity. Individuals with $x_{i} \leq 0$ pay zero taxes. The government wants to eliminate income-tax exemptions, for reasons not specified in our model. We assume that a common abolishment of all exemptions is not possible. The government can cut only some, i.e. at most $m \in \mathcal{N} \backslash\{n\}$ exemptions. For simplicity we consider only a cut of one single exemption $\theta_{n}$ with all other deductions possibilities remaining constant. It does not matter for the analysis if the tax deductability of $\theta_{n}$ is eliminated or only reduced. Furthermore, the results we derive below apply also for reform packages with $m>1$ proportional reductions/abolishments. We summarize all exemptions that remain untouched for individual $i$ by $\beta_{i} \equiv \sum_{j=1}^{n-1} \theta_{i j}$, so that the after-reform tax base is denoted by $z_{i} \equiv y-\beta_{i}$. The distribution of $z_{i} \in \mathbb{R}$ across $\mathcal{I}$ follows some different function $G(z)$, where $z_{i} \geq x_{i} \forall i \in \mathcal{N}$.

\footnotetext{
${ }^{1}$ Barbaro and Südekum (2004) have provided this analysis for the $t c c b b$-policy and for the special case of proportional taxation, equal gross incomes and only two deduction possibilites. The present paper generalizes this approach in various directions, while focussing only on the individual voting behaviour.

${ }^{2}$ The assumption that the $\theta_{i j}^{\prime} s$ are exogenous implies that the agent does not change her behavior because of tax incentives. This assumption can be subject to a "Lucas critique", but is made here to keep the model simple.

${ }^{3}$ The properties of $F(x)$ are not crucial for our model, since we focus on individual voting behavior and not on the society as a whole. It is only needed to specify the budget constraint of the state below. Note, however, that if the number of tax exemptions $n$ is large and if $y_{i}$ and all $\theta_{j}^{\prime} s$ are distributed independently, then $F(x)$ will aproximately follow a normal distribution according to the central limit theorem.
} 


\subsection{Budget-enlargement}

In the first scenario, the entire revenue is spent on redistribution such that each agent receives a lump-sum transfer denoted by $\lambda$. The additional tax revenue created by the cut of the exemption $\theta_{n}$ is used to raise $\lambda$. An agent will support the reform proposal if it increases her net income, or - inter alia - if it decreases her net contribution to the public budget. In the initial scenario this is given by

$$
T\left(y_{i}-\beta_{i}-\theta_{i n}\right)-\lambda_{0}=T\left(x_{i}\right)-\lambda_{0} .
$$

If the reform is implemented, net contribution changes to

$$
T\left(y_{i}-\beta_{i}\right)-\lambda_{1}=T\left(z_{i}\right)-\lambda_{1} .
$$

where $\lambda_{0}$ and $\lambda_{1}$ denote the lump-sum transfers before and after the tax reform, respectively, and

$$
\Delta \equiv \lambda_{1}-\lambda_{0}=\int_{0}^{\infty} T\left(z_{i}\right) d G(z)-\int_{0}^{\infty} T\left(x_{i}\right) d F(x)>0
$$

is the increase of the lump-sum transfer so that the balanced-budget constraint of the state is satisfied. From now on, we focus on those individuals with tax base $x_{i}>0$, since agents who pay no taxes will surely support the be-reform. For individuals with positive tax base it is straightforward to find the critical level $\theta_{\text {in }}$ at which an agent is indifferent between the reform proposal and the initial situation. It is given by

$$
\tilde{\theta}_{i n}=y_{i}-\beta_{i}-T^{-1}\left(T\left(y_{i}-\beta_{i}\right)-\Delta\right) \text {. }
$$

If the individual value $\theta_{i n}$ is smaller (greater) than $\tilde{\theta}_{i n}$, the agent would support (reject) the reform proposal in a direct democratic vote. To avoid complications we restrict our focus a bit further and only look at individuals $T\left(z_{i}\right)>\Delta$. That is, we only consider those individuals whose post-reform total tax payment exceeds the increase in the lump-sum transfer $(\Delta)$. Realistically, this will be the major chunk of the voting population. ${ }^{4}$

Considering (4), the critical value for the support/rejection decision, $\tilde{\theta}_{i n}$, depends on the other exemptions which are not at stake in the government's reform proposal $\left(\beta_{i}\right)$. As a first result we can thus infer that in general the individual voting decision on the tax reform is also affected by how much agent benefits from other deduction possibilities. In particular, differentiating (4) with respect to $\beta_{i}$ yields

$$
\frac{\partial \tilde{\theta}_{i n}}{\partial \beta_{i}}=\frac{T^{\prime}\left(y_{i}-\beta_{i}\right)}{T^{\prime}\left(T^{-1}\left[T\left(y_{i}-\beta_{i}\right)-\Delta\right]\right)}-1 .
$$

With this expression we can derive the following proposition.

\footnotetext{
${ }^{4}$ Note that even with the assumption $T\left(z_{i}\right)>\Delta$ the individual $i$ can still be a net transfer recipient before and after the reform, i.e. both (1) and (2) can be negative.
} 
Proposition 1 The effect of $\beta_{i}$ on the critical value $\tilde{\theta}_{\text {in }}$ is positive (negative) if taxation is directly progressive (regressive). In case of proportional taxation, $\frac{\partial \tilde{\theta}_{i n}}{\partial \beta_{i}}=0$. That is, the individual voting decision on the abolishment of $\theta_{n}$ in exchange for a budget enlargement depends only on how much the voter is affected by this particular deduction possibility.

Proof. Considering that $T^{-1}\left(T\left(y_{i}-\beta_{i}\right)\right)=z_{i}$ and $\Delta>0$ it must be true that $T^{-1}\left(T\left(z_{i}\right)-\Delta\right)<T^{-1}\left(T\left(z_{i}\right)\right)$ with the assumption that $T\left(z_{i}\right)>\Delta$. The argument of the marginal tax-rate function $T^{\prime}(\cdot)$ in the enumerator is greater than in the denominator. In case of a progressive taxation (i.e. $\left.T^{\prime \prime}(\cdot)>0\right)$ eq. (5) is thus positive, and it is negative in case of regressive taxation. With proportional taxation, $T^{\prime}(x)$ is a constant tax rate $t$ for all tax bases $\left(T^{\prime \prime}(\cdot)=0\right)$.

Although $\Delta$ is endogenous and depends on how strongly the voting population as a whole has benefited from the abolished tax exemption $\theta_{n}$ (see eq. (3)), the individual voting decision does not depend on the size of $\Delta$. To get some intuition for the proposition, consider an example where all agents receive the same gross income $\left(y_{i}=\bar{y}\right)$ and benefit uniformly from the exemption $\theta_{n}$ at stake, but not from the other exemptions $\left(\beta_{i}\right)$. Agents with a high $\beta_{i}$ have a small taxable income and face a lower additional tax burden under progressive taxation in case the reform proposal is implemented. As $\Delta$ is the same for all agents, voters with a high $\beta_{i}$ are thus more likely to support the budget enlargement.

It is also interesting to analyse how changes in gross income $y_{i}$ affect the individual voting decision. It is easily verified that $\frac{\partial \tilde{\theta}_{i n}}{\partial y_{i}}=-\frac{\partial \tilde{\theta}_{i n}}{\partial \beta_{i}}$. Therefore, the insights from Proposition 1 can directly be used. Under progressive taxation and for a given $\beta_{i}$, the critical value $\tilde{\theta}_{i n}$ is lower the higher gross income. Richer individuals are more reluctant to support the be-reform, because the broadening of the tax base due to the elimination of $\theta_{n}$ is more costly for them. This result corresponds to the insight that richer agents are usually against tax reforms that aim at more redistribution in the society. Yet, in our model this is true only for the case of progressive taxation. Under proportional taxation the individual voting decision whether to support or reject the abolishment of $\theta_{n}$ in exchange for a budget enlargement is independent of her gross income $\left(\frac{\partial \tilde{\theta}_{i n}}{\partial y_{i}}=0\right)$. In this regime the only determinant of the individual voting decision is how strongly the voter benefits from the deduction at stake. ${ }^{5}$ With regressive taxation individuals with a high gross income (ceteris paribus) will easier support the be-reform.

\subsection{Tax-cut-cum-base-broadening}

In the second scenario, the revenue that is generated by the cut of the exemption $\theta_{n}$ is used to lower tax rates, whereas the lump-sum transfer $\lambda_{0}$ remains unaffected. A single agent will vote in favor of this proposal if her post-reform tax payment is lower than in the initial scenario.

\footnotetext{
${ }^{5}$ For this particular regime one can easily show that an agent will support (reject) the reform proposal if her individual deduction $\theta_{i n}$ is below (above) the average deduction $\bar{\theta}_{n}$ in the population. Equation (1) and (2) can be reworked to $t \cdot\left(x_{i}\right)-\lambda_{0}$ and $t \cdot\left(z_{i}\right)-\lambda_{1}$. The critical value is thus $\tilde{\theta}_{i n}=\frac{\Delta}{t}$. Using (3), we find that $\Delta=t \cdot \bar{\theta}_{n}$, which implies $\tilde{\theta}_{i n}=\bar{\theta}_{n}$.
} 
Assumption 1 The tax rate reduction takes the form of a parallel downward shift of the marginal tax-rate function $T^{\prime}(x)$, so that $T^{\prime \prime}(x)$ remains constant for all tax bases $x$. Let $\delta$ denote the size of the downward shift of the marginal tax rate schedule that can be larger the more the voting population is affected by $\theta_{i n}$. In particular, $\delta$ is given by

$$
\delta=\frac{\int_{0}^{\infty} T_{0}\left(y_{i}-\beta_{i}\right) d G(z)-\int_{0}^{\infty} T_{0}\left(y_{i}-\beta_{i}-\theta_{i n}\right) d F(x)}{\int_{0}^{\infty}\left(y_{i}-\beta_{i}\right) d G(z)}>0
$$

so that the balanced-budget constraint of the state is satisfied.

This assumption greatly simplifies the discussion, because the benefit from decreasing tax rates is independent of $T^{\prime}(x)$. An agent's total tax payment in the initial scenario is given by

$$
T_{0, i} \equiv T_{0}\left(y_{i}-\beta_{i}-\theta_{i n}\right)=T_{0}\left(x_{i}\right)
$$

The post-reform tax payment would be

$$
T_{1, i} \equiv T_{1}\left(y_{i}-\beta_{i}\right)=T_{1}\left(z_{i}\right) .
$$

An individual (with $x_{i}>0$ ) is indifferent between the two scenarios if her individual deduction $\theta_{\text {in }}$ is equal to

$$
\tilde{\theta}_{i n}=y_{i}-\beta_{i}-T_{0}^{-1}\left(T_{1}\left(y_{i}-\beta_{i}\right)\right) \text {. }
$$

With $\theta_{i n}$ smaller (greater) than $\tilde{\theta}_{i n}$ she would support (reject) the reform. Differentiating (9) with respect to $\beta_{i}$ yields

$$
\frac{\partial \tilde{\theta}_{i n}}{\partial \beta_{i}}=\frac{T_{1}^{\prime}\left(y_{i}-\beta_{i}\right)}{T_{0}^{\prime}\left(T_{0}^{-1}\left(T_{1}\left(y_{i}-\beta_{i}\right)\right)\right)}-1 .
$$

With a tccbb-policy, $T_{0}^{\prime}(x)$ is strictly greater than $T_{1}^{\prime}(x)$. On the other hand, the arguments of the marginal tax rate functions in the enumerator and denominator of (10) are not equal. It is helpful to state first

Lemma 1 Using assumption 1, we can write $T_{1}^{\prime}(x)=T_{0}^{\prime}(x)-\delta$, with $\delta>0$. Thus, $T_{1}(x)=T_{0}(x)-\delta x$, which implies that $T_{0}^{-1}\left(T_{1}\left(y_{i}-\beta_{i}\right)\right)=T_{0}^{-1}\left(T_{0}\left(y_{i}-\beta_{i}\right)-\delta\left(y_{i}-\beta_{i}\right)\right)$. This expression is strictly smaller than $y_{i}-\beta_{i}$ since $\delta\left(y_{i}-\beta_{i}\right)>0$.

Using Lemma 1, we can rewrite (10) as

$$
\frac{\partial \tilde{\theta}_{i n}}{\partial \beta_{i}}=\frac{T_{0}^{\prime}\left(y_{i}-\beta_{i}\right)-\delta}{T_{0}^{\prime}\left(T_{0}^{-1}\left(T_{0}\left(y_{i}-\beta_{i}\right)-\delta\left(y_{i}-\beta_{i}\right)\right)\right)}-1 .
$$

This expression is negative if

$$
\delta>T_{0}^{\prime}\left(y_{i}-\beta_{i}\right)-T_{0}^{\prime}\left(\psi_{i}(\delta)\right)
$$


where $\psi_{i}(\delta) \equiv T_{0}^{-1}\left(T_{0}\left(z_{i}\right)-\delta\left(z_{i}\right)\right)<z_{i}$. In the special case of proportional taxation the right hand side of (12) is always equal to zero, because $T_{0}^{\prime}(x)$ is constant. Since $\delta>0$, the condition for $\frac{\partial \tilde{\theta}_{i n}}{\partial \beta_{i}}<0$ is therefore always satisfied. The same is true for regressive taxation, since in this case the right hand side of (12) is even negative as $z_{i}>\psi_{i}(\delta)$ implies that $T_{0}^{\prime}\left(z_{i}\right)<T_{0}^{\prime}\left(\psi_{i}(\delta)\right)$. That is, under proportional and regressive taxation, the more a voter benefits from deduction possibilities that are not at stake, the earlier she will reject the proposal to abolish exemption $\theta_{n}$. Matters are more complicated for the case of progressive taxation, because the right hand side of (12) is also positive as $z_{i}>\psi_{i}(\delta)$ now implies that $T_{0}^{\prime}\left(z_{i}\right)>T_{0}^{\prime}\left(\psi_{i}(\delta)\right)$. Intuitively, if agent $i$ has a tax base $z_{i}$ in an area where the marginal tax rates are not rapidly increasing, then the result $\frac{\partial \tilde{\theta}_{i n}}{\partial \beta_{i}}<0$ will also apply. We provide the following Lemma:

Lemma $2 \frac{\partial \tilde{\theta}_{i n}}{\partial \beta_{i}}$ is negative under progressive taxation if the slope of the marginal tax rate function evaluated at the individual tax base $z_{i}$ fulfills the condition $T_{0}^{\prime \prime}\left(\psi_{i}(\delta)\right)<$ $\frac{T_{0}^{\prime}\left(\psi_{i}(\delta)\right)}{z_{i}}$ (i.e., if it is relatively flat).

Proof. Define $\Phi_{i}(\delta) \equiv T_{0}^{\prime}\left(z_{i}\right)-T_{0}^{\prime}\left(\psi_{i}(\delta)\right)$, which approaches zero as $\delta \rightarrow 0$. Inequality (12) is thus fulfilled if $\frac{\partial \Phi_{i}(\delta)}{\partial \delta}<1$. Taking derivatives, we have

$$
\frac{\partial \Phi_{i}(\delta)}{\partial \delta}=\frac{\left(z_{i}\right) \cdot T_{0}^{\prime \prime}\left(\psi_{i}(\delta)\right)}{T_{0}^{\prime}\left(\psi_{i}(\delta)\right)} .
$$

This expression (13) is below one if

$$
T_{0}^{\prime \prime}\left(\psi_{i}(\delta)\right)<\frac{T_{0}^{\prime}\left(\psi_{i}(\delta)\right)}{z_{i}} .
$$

Inequality (14) specifies the condition how flat the marginal tax rate schedule must be at the individual tax base $z_{i}$ so that $\frac{\partial \tilde{\theta}_{i n}}{\partial \beta_{i}}<0$. With a strictly concave marginal tax rate schedule $\left(T^{\prime \prime}(x)>0, T^{\prime \prime \prime}(x)<0\right)$ and a small downward shift $\delta$ so that $\psi_{i}(\delta) \rightarrow z_{i}$, this condition would always hold. In general we can not rule out $\frac{\partial \tilde{\theta}_{i n}}{\partial \beta_{i}}>0$, but this would require marginal tax rates to rise rapidly.

Combining the insights from this section, we state the following result:

Proposition 2 For proportional, regressive and "non-extreme" progressive taxation (where (14) holds), an individual is less likely to vote for the abolishment of a tax exemption in exchange for lower tax rates (tccbb) the stronger she is affected by other deduction possibilities that are not at stake in the government's reform proposal.

To illustrate the intuition consider again the special case of a proportional income tax system. ${ }^{6}$ Using the budget constraint of the state, we can derive the flat-tax rates

\footnotetext{
${ }^{6}$ This case has been analysed at length in Barbaro and Suedekum (2004). In that paper we assume identical gross incomes and only two initial deduction possibilities. These simplification allow for an analysis of the voting results in the society as a whole. We show that the voting outcome depends on the joint distribution of the tax privileges across the population and point to implicit logrolling as a crucial mechanism that becomes relevant in complicated income tax systems.
} 
before and after the reform, $t_{0}$ and $t_{1}$. They are given by

$$
t_{0}=\frac{\lambda_{0}}{\left(\bar{y}-\bar{\beta}-\bar{\theta}_{n}\right)} \text { and } t_{1}=\frac{\lambda_{0}}{(\bar{y}-\bar{\beta})} .
$$

where a bar over a variable denotes the respective average value in the voting population.

The critical value $\tilde{\theta}_{i n}$ for the support/rejection decision of agent $i$ with respect to the tax-cut-cum-base-broadening reform is then given by

$$
\tilde{\theta}_{i n}=\left(1-\frac{t_{1}}{t_{0}}\right) \cdot\left(y_{i}-\beta_{i}\right)=\left(\frac{\bar{\theta}_{n}}{\bar{y}-\bar{\beta}}\right)\left(y_{i}-\beta_{i}\right)
$$

which depends negatively on $\beta_{i}$. Suppose again that all agents benefit equally from tax exemption $\theta_{n}$ but differently from $\beta_{i}$. In case the tax reform is implemented, each agent has to make an uniform additional tax payment equal to $\bar{\theta}_{n} \cdot t_{1}$. But the benefit of the tax reform, the lower tax rates, matter differently for the single voters, depending on the size of their respective tax base. Those with a low tax base will vote against the reform proposal and, vice versa, those with a large tax base will vote in favor. One reason why the tax base of an individual $i$ is low (apart from differences in gross income $y_{i}$ ) is that she benefits strongly from the other tax exemptions $\beta_{i}$. Since $\frac{\partial \tilde{\theta}_{i n}}{\partial y_{i}}=-\frac{\partial \tilde{\theta}_{i n}}{\partial \beta_{i}}>0$, richer agents will easier support the tax-cut-cum-tax-broadening (except for the case of extreme progression), because the lower tax rates are applied on a larger tax base.

\section{Conclusion}

The individual voting behavior on the abolishment of single income-tax exemptions depends crucially on how strongly agents are affected by other deduction possibilities, even if they play no direct role in the reform plans of the government. An illustrative application of this result is the following: When the government plans to eliminate the tax deductability of commuting expenses, it would be an improper method to assess the political chances of such a reform proposal by looking only at how strong the voting population is affected from this particular tax privilege. The government would have to look at all available tax deduction possibilities (e.g. the tax exemption of work at night, deductions for building homes etc.).

How the interaction of exemptions matters in a complicated income-tax system with several parallel deduction possibilities depends $(i)$ on the shape of the tax schedule, and (ii) on how the government wants to use the revenue that is generated by the cut of tax privileges. In the first scenario, the government plans to increase redistribution in form of lump-sum transfers. The chance that a single individual supports this tax reform increases with the existence of other deduction possibilities under progressive taxation. With proportional taxation and a budget-enlargement policy, the voting decision on a tax reform depends only on the particular tax privileges at stake in the reform proposal, but not on how rich the agent is or how much she benefits from other deduction possibilities. Matters are different if the government wants to adopt a revenue-neutral "tax-cut-cum-base-broadening" policy. Under any plausible income 
tax schedule, it is less likely that an agent supports the elimination of tax privileges the stronger she is affected by other exemptions in the back.

Given that actual tax regimes in continental Europe are characterised $(i)$ by many parallel deduction possilibities, and $(i i)$ by direct progression of tax rates, our paper suggests that the budget enlargement option might be the more promising political strategy for tax reformers.

\section{References}

Barbaro, S., Südekum, J., 2004. Reforming a complicated income-tax system: The political economics perspective. University of Goettingen, Discussion Paper 120.

Fernandez, R., Rodrik, D., 1991. Resistance to reform: Status quo bias in the presence of individual-specific uncertainty. American Economic Review 81 (5), 1146-1155.

Graetz, M. J., 1999. The U.S. Income Tax. Norton, New York.

Hall, Robert, E., Rabushka, A., 1985. The flat tax. Hoover Institution Press, Stanford.

Harms, P., Zink, S., 2003. Limits to redistribution in a democracy: A survey. European Journal of Political Economy 19, 651-668.

Konrad, K. A., 2004. Inverse campaigning. The Economic Journal 114, 69-82.

Meltzer, D., Richard, S., 1981. A rational theory of the size of government. Journal of Political Economy 89, 914-927.

Meltzer, D., Richard, S., 1983. Test of a rational theory of the size of government. Public Choice 41, 403-418.

Roberts, K., 1977. Voting over income tax schedules. Journal of Public Economics 8, 329-340.

Romer, T., 1975. Individual welfare, majority voting and the properties of a linear income tax. Journal of Public Economics 7. 